\title{
Correspondence
}

\section{Retrieving important mass-balance model parameters from AWS measurements and high-resolution mesoscale atmospheric modeling}

Physically based distributed mass-balance models (e.g. Kayastha and others, 1999; Klok and Oerlemans, 2002; Mölg and others, 2009) are our most important tools for understanding observed glacier mass change and attributing this change to particular causes. Like all process-oriented models, they require many parameters that control the specific processes simulated. Among these, two critical but poorly constrained parameters are the density, $\rho_{\mathrm{sp},}$ and the temperature threshold, $\mathrm{TT}_{\mathrm{sp}}$, of solid precipitation on glaciers. The latter specifies at what ambient air temperatures precipitation turns from solid into liquid water. In the literature, both parameters are usually associated with fresh snowfall, although, precisely speaking, they also need to incorporate other solid forms of precipitation, such as graupel, which occurs frequently during convective precipitation events on glaciers (e.g. Mölg and Kaser, 2011). These two parameters exert a major control on the accumulation term in a mass-balance model, and on ablation as well through the snowfall-albedo link. Typically $\rho_{\text {sp }}$ can only be measured on special occasions, i.e. when solid precipitation occurs during fieldwork. Measurements of $\mathrm{TT}_{\mathrm{sp}}$ from remote sites are for the most part unavailable. Unfortunately, uncertainty in these two parameters may significantly affect model results (e.g. Reijmer and Hock, 2008; Mölg and others, 2009).

In a recent paper, Mölg and Kaser (2011) showed for the first time that the atmospheric surface layer over a small mountain glacier can be explicitly resolved in a numerical limited-area atmospheric model (LAM), which captures synoptic-scale atmosphere-ocean dynamics in its computational domain. They also showed that the simulated surface layer conditions can be applied successfully as input to a physically based distributed mass-balance model, eliminating the need for statistical downscaling. This approach opens many prospects for questions on multi-scale linkages in the climate system and on climate-glacier relations. Apart from these big topics, however, we argue that the output from such high-resolution LAMs also serves as a valuable addition to glaciological field programs, in order to improve local cryospheric modeling. In this brief note we demonstrate the determination of the parameters $\rho_{\mathrm{sp}}$ and $\mathrm{TT}_{\mathrm{sp}}$ from a fully physical framework as represented by a LAM, in combination with routine field measurements. Thus, we aim to introduce a new approach for constraining uncertain parameters more objectively in future mass-balance modeling studies, which is of potential interest whenever automatic weather station (AWS) and LAM data are available.

\section{DATA SOURCES}

In contrast to rare measurements of $\rho_{\mathrm{sp}}$, glacier surface height change is nowadays recorded continuously on most AWSs at remote glacier sites, using an ultrasonic ranging sensor (e.g. Hardy and others 2003; Van den Broeke and others, 2004). Interpreting its data - the actual height change - is not trivial, but usually reliable on a daily or greater timescale (Hardy and others, 2003). Here we use the quality-controlled daily sonic ranger data from the top of Kersten Glacier, Kilimanjaro, East Africa, where processes other than precipitation (e.g. snowdrift) have little and infrequent impact on the sensor's accumulation signal (Mölg and others, 2009). Using the short interval of 1 day helps to ensure that measured surface-height increases primarily reflect precipitation, rather than net accumulation over time (cf. fig. 6 in Hardy and others, 2003).

We also consider the output from LAM runs for the same mountain from Mölg and Kaser (2011) who achieved a spatial resolution of $812 \mathrm{~m}$ by multiple grid nesting. This setup adequately resolves the glacierized altitudes on Kilimanjaro, and successfully reproduces the high-altitude meteorological conditions recorded by an AWS on Kersten Glacier. Mölg and Kaser (2011) discuss the quality of the LAM output in detail. Their assessment includes simulated precipitation at the AWS, which was found to perform well in massbalance calculations. LAM data are available for a month of the region's rainy season, April 2006, which is the only simulation period with frequent precipitation events on the glacier. To account for LAM errors and uncertainties, three further runs with slightly changed settings (two concerning initial soil moisture, one a different land surface model) are considered in the present study and were conducted by Mölg and others (2012). Therefore, we analyze in total four April 2006 simulations, henceforth LAM-1 to LAM-4.

\section{DENSITY OF SOLID PRECIPITATION}

In mass-balance models, $\rho_{\mathrm{sp}}$ is required to convert sonic ranger-derived input data to mass or, vice versa, to convert water equivalent input to actual height changes. Assuming that cumulative precipitation is reliably simulated by the LAM, which is justified here (see 'Data sources' above), and therefore that the total accumulation height recorded by the sonic ranger reflects total LAM precipitation, the mean monthly $\rho_{\text {sp }}$ can be determined (Fig. 1a). Accounting for four LAM runs and assuming $\pm 10 \%$ uncertainty in the sonic ranging sensor, which is more pessimistic than its nominal accuracy of $0.01 \mathrm{~m}$, yields $269 \pm 23 \mathrm{~kg} \mathrm{~m}^{-3}(1 \sigma)$. This estimate is in good agreement with the $\sim 250 \mathrm{~kg} \mathrm{~m}^{-3}$ obtained by 2 year long measurements on tropical Glaciar Zongo, Bolivia (Sicart and others, 2002). These measurements represent one of the few datasets where a sonic ranger and a precipitation gauge were operated simultaneously, in order to determine the density of the actual precipitation height directly from field data. Precipitation at relatively high air temperatures (Sicart and others, 2002) and significant amounts of graupel in addition to snow (Mölg and Kaser, 2011) may cause the high mean $\rho_{\text {sp }}$ at low latitudes. At mid- and high latitudes, mean $\rho_{\text {sp }}$ can be $<100 \mathrm{~kg} \mathrm{~m}^{-3}$ (e.g. Judson and Doesken, 2000).

As the typical rainy-season pattern appears in both the sonic ranger record and LAM output, i.e. a succession of wet and dry spells (slopes and plateaus in Fig. 1a, respectively), we can also explore the possibility of inferring $\rho_{\text {sp }}$ on an event basis. For this exercise, we only consider days where the non-dimensional difference between the two data sources (Fig. 1b) is $<20 \%$. LAM- 1 contributes 3 days (indicated in Fig. 1b), and eight more qualify from the other three LAM runs. The resultant daily $\rho_{\text {sp }}$ ranges between 230 

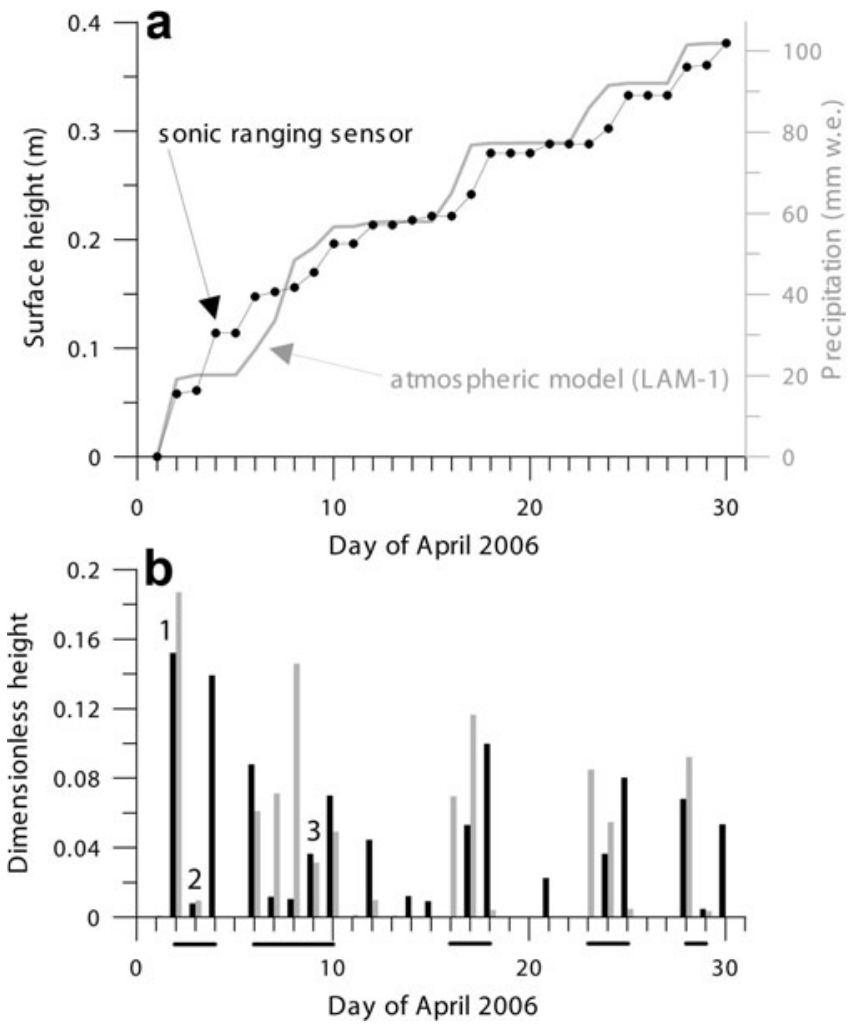

Fig. 1. Actual accumulation recorded by the sonic ranging sensor (black), and water equivalent precipitation simulated by the atmospheric model (gray, here LAM-1), in April 2006 near the summit of Kilimanjaro. (a) Accumulated daily data. (b) Daily precipitation non-dimensionalized by the respective mean value; numbers in the plot indicate selected daily events, and horizontal bars below the $x$-axis localize wet spells.

and $329 \mathrm{~kg} \mathrm{~m}^{-3}$, and obvious correlations exist with simulated mean daily wind speed at $10 \mathrm{~m}\left(V_{10}\right)$ and air temperature at screen level $\left(T_{2 \mathrm{~m}}\right)$ on Kersten Glacier, -0.44 and 0.47 respectively. In a multiple linear regression, these two variables explain $36 \%$ of the variance in daily $\rho_{\text {sp }}$. Due to the small data sample ( $n=11$ days) the correlations are not significant, but they indicate the potential to develop parameterizations of $\rho_{\mathrm{sp}}$ from variables readily measured by an AWS (near-surface wind speed and air temperature) in the future, when longer-term high-resolution LAM simulations will be available. Performing the same exercise with clusters of wet days as events (horizontal bars below $x$-axis in Fig. 1b), or with anomalies of $\rho_{\mathrm{sp}}, V_{10}$ and $T_{2 \mathrm{~m}}$, did not lead to other insights.

\section{TEMPERATURE THRESHOLD OF SOLID PRECIPITATION}

For distributed mass-balance modeling, the input record of total precipitation is usually distributed across the glacier by an air-temperature threshold that separates solid from liquid precipitation (e.g. Klok and Oerlemans, 2002) or by two such thresholds between which the solid vs liquid fraction is linearly interpolated (e.g. Reijmer and Hock, 2008). The input should therefore always be all-phase precipitation. Some authors have also incorporated relative humidity in the distribution algorithm (e.g. Kayastha and others, 1999). In general, the methodology and choice of thresholds vary widely between studies. LAM output provides a physical constraint for the temporal resolutions at which processbased mass-balance models are run ( $\leq 1$ hour). Although the simulated hydrometeor species in LAMs are a three-dimensional field, we only look at the lowest layer directly above the terrain (here $\sim 58 \mathrm{~m}$ ) since the altitude separating rain and snow can be hundreds of meters higher in the free air upwind than on the mountainside (Minder and others, 2011).

In Figure 2 we consider the mountain section from $4000 \mathrm{~m}$ a.s.l. to the peak of Kilimanjaro (5573 $\mathrm{m}$ a.s.l. in the LAM), to ensure the temperature range for the analysis is large enough. The hourly relation between $T_{2 \mathrm{~m}}$ and the fraction of solid precipitation shows expected scatter (Fig. 2a), but also reveals that values are concentrated near $100 \%$ or at $0 \%(81 \%$ of all points lie above the $90 \%$ or below the $10 \%$ fraction). The analysis by temperature bins (Fig. 2b) suggests that linear interpolation is reasonable if mean values are considered, here in a $T_{2 \mathrm{~m}}$ range from $-4^{\circ} \mathrm{C}$ to $+4^{\circ} \mathrm{C}$ for the full transition from solid to liquid precipitation. This range is larger than what is considered in most mass-balance model studies. It should not be regarded as site-specific, though, but rather representative of convective precipitation events. For example, the transition zone at mid-latitude shows a similarly broad range during convective events (e.g. Liu and Moncrieff, 2007).

However, Figure $2 \mathrm{~b}$ also demonstrates that for temperature bins from $-2^{\circ} \mathrm{C}$ to $1.5^{\circ} \mathrm{C}$ the mean is not a good
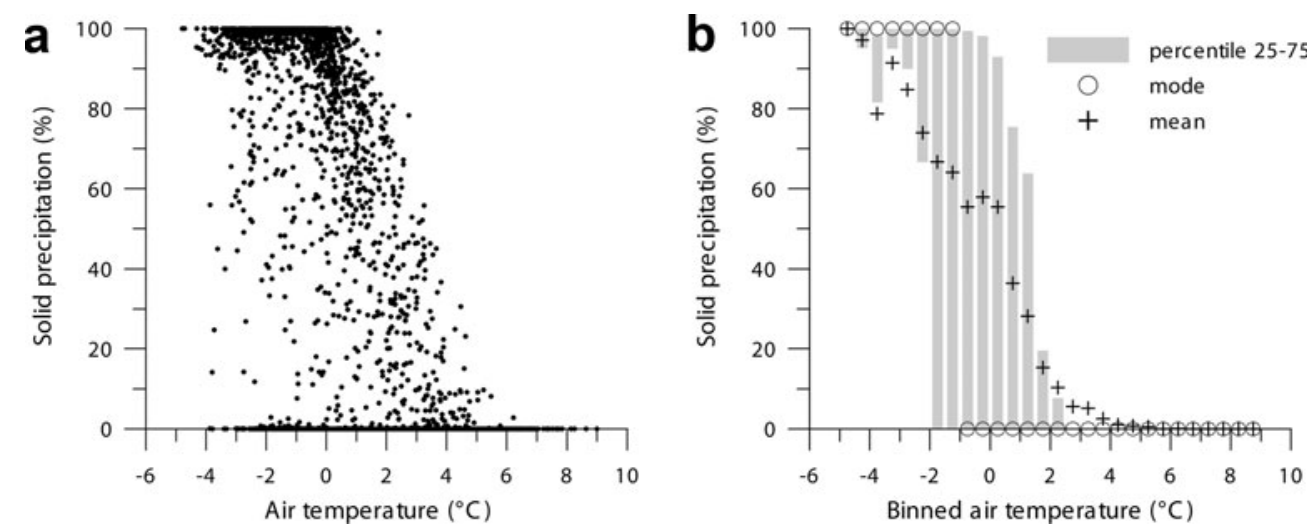

Fig. 2. (a) Hourly $2 \mathrm{~m}$ air temperature versus the fraction of solid precipitation (snow + graupel + hail) on the lowermost atmospheric model layer in the April 2006 simulation (LAM-1). (b) Different statistics of the data in (a) for air-temperature bins of $0.5^{\circ} \mathrm{C}$ width. Analysis for altitudes above $4000 \mathrm{~m}$ a.s.I. in the innermost LAM domain. 


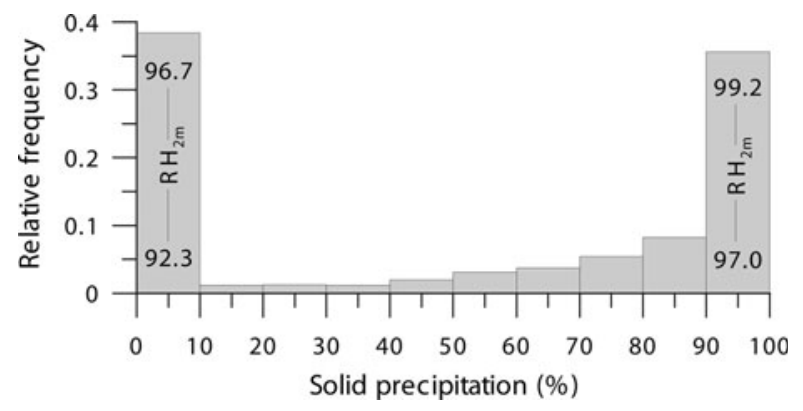

Fig. 3. Histogram of solid precipitation fraction in the $2 \mathrm{~m}$ airtemperature interval -2 to $1.5^{\circ} \mathrm{C}$. Numbers inside bars show percentile 20 and 80 of the $2 \mathrm{~m}$ relative humidity $\left(\mathrm{RH}_{2 \mathrm{~m}}\right)$ for the two dominant classes at the tails, which suggests a separation threshold of $97 \%$ relative humidity.

representation of the data sample, since the distributions are strongly $U$-shaped (the percentiles 25 and 75 closely approximate the $y$-axis minimum and maximum, respectively). A step-like transition from solid to liquid precipitation, here at $-1{ }^{\circ} \mathrm{C}$ where the mode switches (Fig. 2b), could therefore also be argued for. For this approach the $T_{2 \mathrm{~m}}$ interval with the U-distribution is problematic, but we find that relative humidity at screen level is an effective predictor for the actual tail of the distribution at the resolved timescale (Fig. 3). Thus the parameterization of precipitation phase from $T_{2 \mathrm{~m}}$ alone is not straightforward, which is consistent with the complexity of mesoscale dynamical processes that control the snow-rain transition in mountains (Minder and others, 2011). Hence, different approaches and their sensitivity characteristics should be considered in massbalance model uncertainty determinations. Figures 2 and 3 are from LAM-1 output, but LAM-2 to LAM-4 outputs provide a consistent result.

\section{CONCLUDING REMARKS AND OUTLOOK}

Running mesoscale atmospheric models at high spatial resolutions (order $10^{1}-10^{2} \mathrm{~m}$ ) is common in weather research and dynamic meteorology, but not established in glaciological research. One exception is the use of highresolution LAMs in 'local' set-up (i.e. one domain and forcing by local atmospheric profiles from the upstream zone) for studying local winds and snow distribution (Lehning and others, 2008). Resolving mountain glaciers and their atmospheric surface layer explicitly in LAMs that downscale large-scale climate dynamics to local meteorological conditions, on the other hand, is a recent development and can drastically improve our understanding of multi-scale linkages in the climate system (Mölg and Kaser, 2011). Besides this, the output from such simulations provides a great opportunity to constrain glacier model parameters in a way that is consistent with the region's synoptic-scale dynamics and governing physical processes across the scales.

Here we have demonstrated the potential of this approach for the density and temperature threshold of solid precipitation on glaciers, which are often 'best-guess' values in mass-balance studies. Other candidate parameters include altitudinal gradients of meteorological variables (Mölg and Kaser, 2011). For our chosen parameters, the sonic ranger measurements must primarily reflect precipitation and not other processes like wind drift or avalanche activity. Therefore, field experience is indispensable to evaluate what the sonic ranger signal is recording (Hardy and others, 2003). If this experience exists, however, routine measurements together with high-resolution atmospheric modeling are a powerful combination for improving cryospheric studies in all climate zones of the Earth. We should therefore increasingly run atmospheric models in addition to on-site measurements, or seek expert collaboration, as one way of reducing parameter uncertainty in glacier mass-balance models.

\section{ACKNOWLEDGEMENTS}

This research was supported by the Alexander von Humboldt Foundation. The comments of Regine Hock and an anonymous reviewer helped to clarify the paper.

Institute of Ecology,

Thomas MÖLG

Technische Universität Berlin, Dieter SCHERER

Berlin, Germany

E-mail: thomas.moelg@uibk.ac.at

\section{March 2012}

\section{REFERENCES}

Hardy DR, Vuille M and Bradley RS (2003) Variability of snow accumulation and isotopic composition on Nevado Sajama, Bolivia. J. Geophys. Res., 108(D22), 4693 (doi: 10.1029/ 2003JD003623)

Judson A and Doesken N (2000) Density of freshly fallen snow in the central Rocky Mountains. Bull. Am. Meteorol. Soc., 81(7), 1577-1587 (doi: 10.1175/1520-0477(2000)081<1577: DOFFSI>2.3.CO;2)

Kayastha RB, Ohata T and Ageta Y (1999) Application of a mass-balance model to a Himalayan glacier. J. Glaciol., 45(151), 559-567

Klok EJ and Oerlemans J (2002) Model study of the spatial distribution of the energy and mass balance of Morteratschgletscher, Switzerland. J. Glaciol., 48(163), 505-518 (doi: 10.3189/172756502781831133)

Lehning M, Löwe H, Ryser M and Radeschall N (2008) Inhomogeneous precipitation distribution and snow transport in steep terrain. Water Resour. Res., 44(W7), W07404 (doi: 10.1029/ 2007WR006545)

Liu C and Moncrieff MW (2007) Sensitivity of cloud-resolving simulations of warm-season convection to cloud microphysics parameterizations. Mon. Weather Rev., 135(8), 2854-2868 (doi: 10.1175/MWR3437.1)

Minder JR, Durran DR and Roe JH (2011) Mesoscale controls on the mountainside snow line. J. Atmos. Sci., 68(9), 2107-2127 (doi: 10.1175/JAS-D-10-05006.1)

Mölg T and Kaser G (2011) A new approach to resolving climatecryosphere relations: downscaling climate dynamics to glacier-scale mass and energy balance without statistical scale linking. J. Geophys. Res., 116(D16), D16101 (doi: 10.1029/ 2011JD015669)

Mölg T, Cullen NJ, Hardy DR, Winkler M and Kaser G (2009) Quantifying climate change in the tropical midtroposphere over East Africa from glacier shrinkage on Kilimanjaro. J. Climate, 22(15), 4162-4181 (doi: 10.1175/2009JCLI2954.1)

Mölg T, Grosshauser M, Hemp A, Hofer M and Marzeion B (2012) Limited forcing of glacier loss through land-cover change on Kilimanjaro. Nature Climate Change (doi: 10.1038/ nclimate1390) 
Reijmer CH and Hock $\mathrm{R}$ (2008) Internal accumulation on Storglaciären, Sweden, in a multi-layer snow model coupled to a distributed energy- and mass-balance model. J. Glaciol., 54(184), 61-72 (doi: 10.3189/002214308784409161)

Sicart JE, Ribstein P, Chazarin JP and Berthier E (2002) Solid precipitation on a tropical glacier in Bolivia measured with an ultrasonic depth gauge. Water Resour. Res., 38(10), 1189 (doi: 10.1029/2002WR001402)

Van den Broeke MR, Reijmer CH and Van de Wal RSW (2004) A study of the surface mass balance in Dronning Maud Land, Antarctica, using automatic weather stations. J. Glaciol., 50(171), 565-582 (doi: 10.3189/172756504781829756) 